\title{
Elucidating the Behavior of Cyclic Volatile Methylsiloxanes in a Subarctic Freshwater Food Web: A Modeled and Measured Approach
}

Ingjerd S. Krogseth, ${ }^{* \dagger \odot ~ E m m a ~ U n d e m a n, ~}{ }^{\ddagger, \S}$ Anita Evenset, ${ }^{\|, \perp}$ Guttorm N. Christensen, ${ }^{\|}$ Mick J. Whelan, ${ }^{\#}$ Knut Breivik, $\nabla, \bigcirc$ and Nicholas A. Warner ${ }^{\dagger}$

${ }^{\dagger}$ NILU - Norwegian Institute for Air Research, The Fram Centre, P.O. Box 6606 Langnes, 9296 Tromsø, Norway

${ }^{\ddagger}$ Baltic Sea Centre, Stockholm University, SE-106 91 Stockholm, Sweden

${ }^{\S}$ Department of Environmental Science and Analytical Chemistry, Stockholm University, Svante Arrhenius väg 8, SE-106 91, Stockholm, Sweden

"Akvaplan-niva AS, The Fram Centre, P.O. Box 6606 Langnes, 9296 Tromsø, Norway

${ }^{\perp}$ Faculty of Biosciences, Fisheries and Economics, UiT the Arctic University of Norway, Hansine Hansens veg 18, 9019 Tromsø, Norway

${ }^{\#}$ School of Geography, Geology and the Environment, University of Leicester, Leicester LE1 7RH, United Kingdom

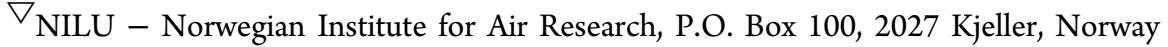

ODepartment of Chemistry, University of Oslo, P.O. Box 1033, Blindern, 0315 Oslo, Norway

Supporting Information

ABSTRACT: Cyclic volatile methylsiloxanes (cVMS) are used in personal care products and emitted to aquatic environments through wastewater effluents, and their bioaccumulation potential is debated. Here, a new bentho-pelagic version of the ACC-HUMAN model was evaluated for polychlorinated biphenyls (PCBs) and applied to cVMS in combination with measurements to explore their bioaccumulation behavior in a subarctic lake. Predictions agreed better with measured PCB concentrations in Arctic char (Salvelinus alpinus) and brown trout (Salmo trutta) when the benthic link was included than in the pelagic-only model. Measured concentrations of decamethylcyclopentasiloxane (D5) were $60 \pm 1.2$ (Chironomidae larvae), $107 \pm 4.5$ (pea clams Pisidium sp.), $131 \pm 105$ (three-spined sticklebacks: Gasterosteus aculeatus), $41 \pm 38$ (char), and $9.9 \pm 5.9$ (trout) $\mathrm{ng} \mathrm{g}^{-1}$

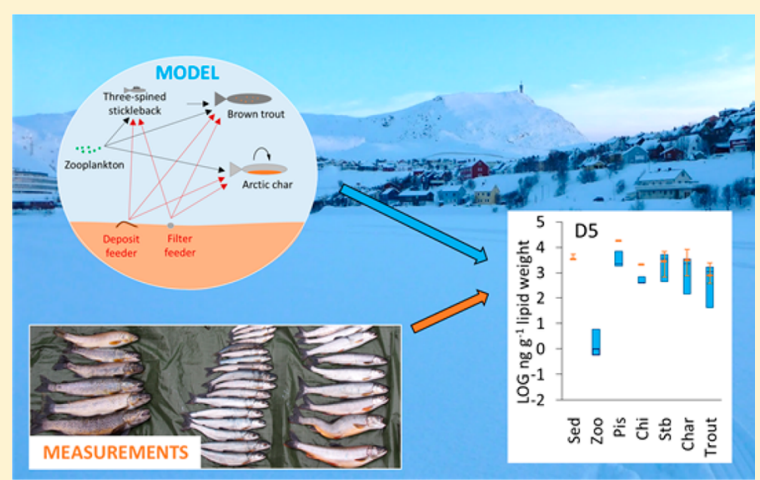
wet weight. Concentrations were lower for octamethylcyclotetrasiloxane (D4) and dodecamethylcyclohexasiloxane (D6), and none of the cVMS displayed trophic magnification. Predicted cVMS concentrations were lower than measured in benthos, but agreed well with measurements in fish. cVMS removal through ventilation was an important predicted loss mechanism for the benthic-feeding fish. Predictions were highly sensitive to the partition coefficient between organic carbon and water $\left(K_{\mathrm{OC}}\right)$ and its temperature dependence, as this controlled bioavailability for benthos (the main source of cVMS for fish).

\section{INTRODUCTION}

Cyclic volatile methyl siloxanes (cVMS), such as octamethylcyclotetrasiloxane (D4), decamethylcyclopentasiloxane (D5), and dodecamethylcyclohexasiloxane (D6), are used as ingredients in personal care products and are emitted to aquatic environments through wastewater effluents. ${ }^{1-3}$ D4 has been classified as a persistent, bioaccumulative, and toxic (PBT) substance and D5 as a very persistent and very bioaccumulative ( $\mathrm{vPvB}$ ) substance in a European Chemical Agency Member State Committee opinion. ${ }^{4}$ A restriction on use in wash-off products is currently underway in Europe..$^{5}$ However, their hazardous properties, particularly their bioaccumulation potential, are uncertain. ${ }^{6-8}$ Field studies of cVMS in aquatic food webs have demonstrated both trophic dilution ${ }^{9-12}$ and trophic magnification, ${ }^{13,14}$ and the explanation(s) for this variability remains unclear. Possible influencing factors include behavioral and physiological characteristics of the investigated taxa, food chain composition, and the nature of the physical environment (including possible confounding effects such as spatial gradients in concentrations). ${ }^{7,15}$

As well as being very volatile, cVMS are very hydrophobic, and are expected to partition significantly to organic phases. Although it is now well established that the organic carbon (OC) to water partition coefficients $\left(K_{\mathrm{OC}}\right)$ for $\mathrm{cVMS}$ are lower than those expected from their octanol to water partitioning

Received: June 16, 2017

Revised: September 8, 2017

Accepted: October 5, 2017

Published: October 5, 2017 
$\left(K_{\mathrm{OW}}\right){ }^{16-19}$ there is uncertainty in the temperature dependence of $K_{\mathrm{OC}}$ which currently constrains our understanding of the behavior of cVMS in cold aquatic environments. ${ }^{20}$ Although a positive relationship between $K_{\mathrm{OW}}$ and temperature has been reported (suggesting lower hydrophobicity at low temperatures), ${ }^{19,21,22}$ a negative relationship between $K_{\mathrm{OC}}$ and water was recently reported (suggesting higher hydrophobicity at low temperatures). ${ }^{23}$ This will influence the behavior of these compounds in systems with low temperatures. In aquatic systems without continuous wastewater emissions, the exposure of pelagic organisms to these compounds is likely to be primarily via benthic links in the food web, as cVMS may be rapidly removed from water between emission events. ${ }^{20}$

The combination of fugacity-based models and measurements has proved useful for developing an understanding of the environmental behavior of cVMS and the identification of key knowledge gaps. ${ }^{24-27}$ However, this approach has rarely been used for cVMS behavior in food webs. Exceptions include applications of the AquaWeb ${ }^{6}$ and ACC-HUMAN models. ${ }^{24,28}$ ACC-HUMAN predicted trophic dilution of cVMS in zooplankton, herring, and cod from the Inner Oslofjord (which receives high wastewater emissions), in accordance with measurements. ${ }^{24}$ However, given the importance the sediments have as a reservoir of cVMS, there is a need for a benthic link in the model. This is particularly important for systems such as Storvannet where fugacities in sediment often exceed those in the water column due to intermittent emission events and rapid advection of the water column. ${ }^{20}$ Here, we explore the bioaccumulation behavior of cVMS using the ACCHUMAN model, which was expanded to include a benthic link. Model performance was first evaluated for well-known PCBs, and the model was subsequently applied to explain measured cVMS concentrations in biota sampled from Lake Storvannet in Northern Norway. Lake Storvannet was chosen as (i) the lake and its food web is relatively well-studied, ${ }^{29,30}$ (ii) measurements of PCBs from lake water, sediments, and biota are available for model evaluation purposes, ${ }^{31}$ and (iii) a study of cVMS behavior in the physical environment of the lake has already been carried out. ${ }^{20}$

\section{MATERIALS AND METHODS}

2.1. Study Site. Lake Storvannet is a small $\left(0.2 \mathrm{~km}^{2}\right.$, maximum depth $17 \mathrm{~m}$ ), oligotrophic lake, located in a residential area of the town of Hammerfest in Northern Norway $\left(70^{\circ} \mathrm{N} 23^{\circ} \mathrm{E} ; 7000\right.$ inhabitants). ${ }^{20}$ The lake has a long history of local contamination with organic contaminants including PCBs. ${ }^{31}$ Untreated wastewater from Hammerfest is now emitted into the sea. However, sewers run along both sides of Storvannet, and the lake unintentionally receives wastewater through leaking pipes and combined sewer overflow events (CSOs), particularly during the snowmelt season and after heavy rainfalls. ${ }^{20}$ As a result, cVMS are present in sediments of the lake with concentrations comparable to much more populated areas $(207 \pm 30,3775 \pm 973$, and $848 \pm 211 \mathrm{ng}$ $\mathrm{g}^{-1}$ OC for D4, D5, and D6, respectively). ${ }^{20}$ However, cVMS were not detected in water samples from the lake (LOQ 19-40 ng L $\mathrm{L}^{-1}, 12-54 \mathrm{ng} \mathrm{L}^{-1}$, and $42-74 \mathrm{ng} \mathrm{L}^{-1}$ for D4, D5, and D6, respectively). ${ }^{20}$ The lake is ice covered for approximately six months of the year and the summer season and the plankton bloom is short. Benthic Chironomidae larvae (hereafter; chironomids) and pea clams (Pisidium sp.) are, consequently, important dietary items for resident fish. ${ }^{29,32,33}$ Populations of both stationary and anadromous Arctic char (Salvelinus alpinus) (hereafter; char) and brown trout (Salmo trutta) (hereafter; trout), as well as three-spined sticklebacks (Gasterosteus aculeatus) (hereafter; sticklebacks) inhabit the lake. ${ }^{29,30}$ While char mostly feed on benthos, the trout has a more pelagic diet including aquatic insects. ${ }^{29,34,35}$ Both the trout and char may be cannibalistic, but the trout tends to be more piscivorous than the char and also feed on sticklebacks (Figure 1, Table 1, Supporting Information (SI) 2.2). The sticklebacks feed on plankton and benthos in the littoral zone of the lake. Only stationary fish were included in this study.

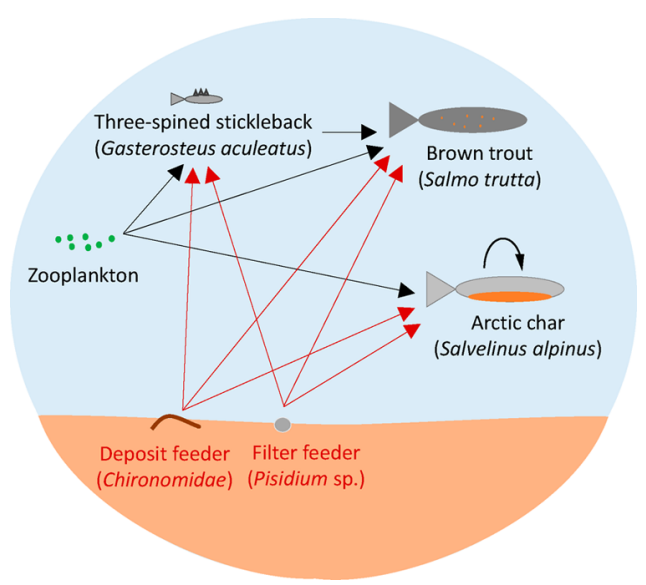

Figure 1. Illustration of the food web in Storvannet as parametrized in ACC-HUMAN. The red labels and arrows show new species and dietary links in the bentho-pelagic version of the model.

2.2. Sample Collection, Preparation, and Analysis. Char $(n=11)$ and trout $(n=13)$ were caught opportunistically in March, May, and June 2014 (SI Table S1). In March and May, the fish were caught with lines and hooks. In June, gill nets were used. In addition, traps, baited with fish roe (wrapped in fine mesh so the fish could not eat it), were deployed in shallow areas of the lake for collection of sticklebacks $(n=5)$. Benthic fauna (Chironomidae and Pisidium sp.) were collected by hauling a $500 \mu \mathrm{m}$ trawl along the bottom. All samples were wrapped in aluminum foil, placed in zip-lock bags, and transported in chilled boxes to the lab where they were stored at $-20{ }^{\circ} \mathrm{C}$ until sample preparation. All use of personal care products was avoided by field and lab personnel. Muscle and liver tissues from Atlantic cod (Gadus morhua) caught off the Norwegian coast were utilized as blank material. Prior to sample collection, the cod tissues were split into three separate portions to serve as field blanks, dissection blanks, and reference blanks, in order to assess if any contamination occurred during field work or sample dissection.

Strict quality control procedures were enforced to limit cVMS contamination of samples (SI 1.1). The bodyweight and total length of each fish were recorded, gender and maturity were determined through visual inspection of the gonads, and stomach content was visually examined (SI Table S1, S2). Otoliths were retrieved to determine the age of the char and trout (SI Table S1). Liver and dorsal muscle tissue was taken out for analysis of cVMS, extractable organic matter (assumed representative for lipids), ${ }^{36}$ and stable isotope analysis (muscle only; $\delta^{15} \mathrm{~N}, \delta^{13} \mathrm{C}, \delta^{14} \mathrm{~S}$ ) (SI 1.2, Table 2). Prior to analyses, both liver and muscle samples were homogenized with a metal scalpel on a clean glass surface. Due to the small size of the sticklebacks, the whole fish was homogenized and the 
Table 1. Summary of Model Parameters for Biota in Storvannet ${ }^{a}$

\begin{tabular}{|c|c|c|c|c|c|}
\hline & chironomids & pisidium & sticklebacks & Arctic char & brown tro \\
\hline age $(y)$ & $0-3$ & $0-3$ & $0-5$ & $0-10$ & $0-10$ \\
\hline mass (mg or $\mathrm{g}$ ) & $0.5-10 \mathrm{mg}$ & $0.1-5 \mathrm{mg}$ & $0.2-1.4 \mathrm{~g}$ & $10-230 \mathrm{~g}$ & $10-390$ \\
\hline length $(\mathrm{cm})$ & $0.1-1.0$ & $0.1-0.5$ & $3-6$ & $10-30$ & $10-34$ \\
\hline lipids (\%) & 3.0 & 0.6 & 4.0 & 1.0 & 1.0 \\
\hline time in sediment $(\%)$ & 80 & 100 & & & \\
\hline \multicolumn{6}{|c|}{ Dietary Composition (\%) } \\
\hline sediment & 100 & 100 & & & \\
\hline zooplankton & & & 20 & $25-30$ & $50-80$ \\
\hline deposit feeder & & & 60 & $45-50$ & $10-20$ \\
\hline filter feeder & & & 20 & $10-20$ & 10 \\
\hline sticklebacks & & & & $0-16$ & $0-30$ \\
\hline Arctic char & & & & $0-7.5$ & \\
\hline
\end{tabular}

${ }^{a}$ See SI 2.2 for all details including how the parameters were derived and their references. The dietary composition in the table is by wet weight, while Figure S7 shows the dietary composition in terms of lipids for char and trout.

Table 2. Ranges (Minimum-Maximum) and Average \pm Standard Deviation of Measured Concentrations of $\left.\mathrm{cVMS}^{\left(\mathrm{ng} \mathrm{g}^{-1}\right.} \mathrm{ww}^{\mathrm{C}}\right)$ (See Tables S6 and S7 for Details) ${ }^{a}$

\begin{tabular}{|c|c|c|c|c|c|c|c|}
\hline & $n$ & $\delta^{15} \mathrm{~N}$ & $\delta^{13} \mathrm{C}$ & lipids (\%) & D4 (ng g $\left.{ }^{-1} w w\right)$ & D5 (ng g $\left.{ }^{-1} w w\right)$ & D6 (ng g $\left.{ }^{-1} w w\right)$ \\
\hline $\begin{array}{l}\text { brown trout } \\
\text { (muscle) }\end{array}$ & 13 & $12.4 \pm 0.9$ & $-24.2 \pm 1.1$ & $1.2 \pm 0.3$ & $<$ LOQ & $\begin{array}{l}3.9-22 \\
9.9 \pm 5.9\end{array}$ & $<\mathrm{LOQ}$ \\
\hline $\begin{array}{l}\text { Arctic char } \\
\text { (muscle) }\end{array}$ & 11 & $10.4 \pm 1.0$ & $-25.2 \pm 0.8$ & $1.0 \pm 0.2$ & $<$ LOQ - 19 & $\begin{array}{l}7.1-124 \\
41 \pm 38\end{array}$ & $<$ LOQ - 6.1 \\
\hline $\begin{array}{l}\text { sticklebacks } \\
\text { (whole fish) }\end{array}$ & 5 & $10.6 \pm 0.5$ & $-24.2 \pm 3.4$ & 4.1 & $\begin{array}{l}4.1-28 \\
13 \pm 9.2\end{array}$ & $\begin{array}{l}28-283 \\
131 \pm 105\end{array}$ & $\begin{array}{l}2.6-12 \\
6.3 \pm 3.6\end{array}$ \\
\hline Chironomidae & 2 & 6.8 & -29.6 & 3.0 & $9.9 \pm 0.3$ & $60 \pm 1.2$ & $9.3 \pm 0.1$ \\
\hline Pisidium sp. & 2 & 4.2 & -31.4 & 0.6 & $4.7 \pm 0.4$ & $107 \pm 4.5$ & $12 \pm 1.2$ \\
\hline
\end{tabular}

${ }^{a}$ Averages and standard deviations have only been calculated where all samples were above LOQ. Concentrations in char and trout are for muscle tissue. Concentrations in benthos have added uncertainty (see section 3.1). Stable isotope information as well as lipid content has also been included (see SI Tables S1 and S2 for details). Lipid content for benthos is derived from literature (SI 2.2.2.2 and 2.2.3.2).

homogenate was analyzed for cVMS and stable isotopes. The collected chironomids were pooled and homogenized in a mortar, giving two replicates for cVMS analysis and one for stable isotopes. The same procedure was followed with whole Pisidium samples (including the carbonaceous shell).

All samples were extracted for cVMS using a biphasic cold solvent extraction, based on a previously published method for sediments, ${ }^{20}$ but adapted to biotic tissues (SI 1.3). Analysis of cVMS was carried out on an Agilent 7890A GC connected to an Agilent 5975C MS detector and a Gerstel MPS3 autosampler. Method details have previously been published. ${ }^{20}$ Calculation of limits of detection (LOD) and quantification (LOQ) from blank samples is described in SI 1.1.

2.3. Bioaccumulation Modeling. 2.3.1. Development of the Bentho-Pelagic ACC-HUMAN. The aquatic part of the original ACC-HUMAN model represents a pelagic Baltic Sea food web consisting of zooplankton, a planktivorous fish (herring) and a piscivorous fish (cod). ${ }^{28}$ Here, a benthic link was included in the model by adding a sediment compartment, a benthic filter feeder, a benthic predator/deposit feeder, and up to three prey items for the latter. The model does not simulate chemical transfer between lake water and sediment. Rather, time-resolved concentrations or fugacities in sediment and lake water is provided as input to the model. Sediment pore water and sediment solids are assumed to be in equilibrium.

The prey items are defined by their biochemical composition (fractions of water, lipid, and nonlipid organic matter), the fraction of time they spend buried in sediments, and assumed thermodynamic equilibrium with their surroundings. Bioaccu- mulation in the predator/deposit feeder and filter feeder are predicted using a dynamic version of the steady-state model of Arnot and Gobas. ${ }^{37}$ The fugacity capacity (Z-value) of the organism is calculated based on its biochemical composition. Chemical uptake occurs through feeding and ventilation (of sediment pore water and/or overlying water). Elimination of chemicals can occur through ventilation, fecal egestion and/or biotransformation. The predator/deposit feeder may feed on the prey items and/or sediment particles, while the filter feeder may feed on suspended or settled sediment particles and/or zooplankton. The fish in the model may prey on the benthic filter feeder and the deposit feeder, in addition to zooplankton and fish. The model assumes annual constant growth rate, lipid content, and dietary composition. However, a seasonal feeding pattern for the fish was included in the model, in which the fish are assumed not to eat during wintertime (NovemberFebruary) as is the case in Storvannet. All equations, parameters, and assumptions for the new model are described in SI 2.1 and 2.2.

To adapt the bentho-pelagic ACC-HUMAN to Storvannet, the model organisms were parametrized as key species of the Storvannet food web. Benthos were parametrized as chironomid larvae (deposit feeder) and Pisidium clams (filter feeder). The pelagic fish was reparametrized based on sticklebacks, while the piscivorous fish was reparametrized to represent either char or trout (SI 2.2, Table 1). Dietary composition of the organisms and overall structure of the food web was based on existing knowledge about the system aided by analysis of stable isotopes and gut content. Measurements of 
water temperatures (SI Table S11), ${ }^{38}$ fraction of solids in sediments $(18 \% \mathrm{v} / \mathrm{v})$ and fraction of OC in sediment solids $(5 \% \mathrm{w} / \mathrm{w})^{20}$ from Storvannet were used as model input.

2.3.2. Model Evaluation and Application. Many model aspects are independent of the compounds studied and are best constrained on the basis of data-rich chemicals like PCBs. To evaluate the performance of the new bentho-pelagic model version, it was compared with the pelagic-only version of ACCHUMAN parametrized for the taxa present in Storvannet. Predicted concentrations in char and trout were compared to measurements from Storvannet for five PCB congeners (SI 2.3).

Empirical data for exposure-relevant physical media are restricted to sediment for cVMS. Hence, only the benthopelagic model version was applied to cVMS, as the pelagic-only model needs concentrations in water as input. Average measured concentrations of cVMS in surface sediments $(0-1$ $\mathrm{cm}$, OC-normalized) of Storvannet in 2014 were used as input to the model (SI Table S13). ${ }^{20}$ cVMS concentrations in Storvannet lake water sampled at the same time were below limits of quantification (LOQ). ${ }^{20}$ Given the lack of measured concentrations, a range of values for the fugacity in water was evaluated, and expressed relative to the fugacity in sediment derived by the model from the concentration in sediment (SI 2.4).

Measured partition coefficients $\left(K_{\mathrm{OW}}\right.$ and $K_{\mathrm{AW}}$ (air-water partitioning $))$ and their temperature dependencies $\left(\Delta U_{\mathrm{OW}}\right.$ and $\Delta U_{\mathrm{AW}}$ ) were used as input (SI Table S13). ${ }^{19,20,39}$ The $K_{\mathrm{OC}}$ values for cVMS are known to be significantly overestimated by empirical relationships with $K_{\mathrm{OW}} \cdot{ }^{19,39}$ This deviation may also apply for $\Delta U_{\mathrm{OC}}$ versus $\Delta U_{\mathrm{OW}}$. The most recently measured values of $K_{\mathrm{OC}}$ and $\Delta U_{\mathrm{OC}}$ for cVMS were, therefore, used as direct inputs, rather than relying on relationships based on affinity to octanol (SI Table S13). ${ }^{18,23}$ That said, partitioning to lipids was still assumed to be represented by partitioning to octanol, ${ }^{40,41}$ although there is limited evidence to justify this assumption. cVMS may undergo biotransformation in aquatic biota, but few measurements are available. Here, a fish biotransformation rate constant $\left(k_{\mathrm{M}}\right)$ of $4 \times 10^{-4} \mathrm{~h}^{-1}$ (corresponding to a half-life of 72 days) was applied for all cVMS (SI Table S13), following Whelan and Breivik. ${ }^{24,42}$ In the absence of evidence, cVMS were assumed to not biotransform in benthos or zooplankton.

The model was run for 10 years with a $1 \mathrm{~h}$ simulation time step. Predicted median lipid-normalized concentrations in year 10 across all age classes at the time of year when the samples were collected, as well as the annual range (min-max), were compared to measured lipid-normalized concentrations in whole-body homogenates (chironomids, Pisidium, and sticklebacks) and in muscle tissue (char and trout). As the model does not provide gender- and/or maturity-specific results for fish, measurements were grouped irrespective of gender and maturity for comparison to model results. Additional simulations were carried out to test the sensitivity of model results to changes in cVMS physical-chemical properties and biotransformation rates (properties were changed individually by $\pm 10 \%$ and $\pm 20 \%)$.

\section{RESULTS AND DISCUSSION}

3.1. Measured Concentrations of cVMS. All cVMS concentrations in benthos were above LOQ (SI Table S3). The D4, D5, and D6 whole body concentrations (pooled duplicates) in chironomids were $9.9 \pm 0.3,60 \pm 1.2$, and 9.3 $\pm 0.1 \mathrm{ng} \mathrm{g}^{-1}$ wet weight (ww), and in Pisidium $4.7 \pm 0.4,107 \pm$ 4.5 , and $11.8 \pm 1.2 \mathrm{ng} \mathrm{g}^{-1}$ ww, respectively (Table 2 ). The measured concentrations in benthos are within the range of measured concentrations in benthos reported elsewhere, including chironomids and burrowing mayfly in Lake Pepin, ragworm in the Humber Estuary, and polychaets from the Oslofjord (SI Table S8). ${ }^{9,10,43,44}$ Lipid content for benthos was not measured due to insufficient sample material. Instead this was derived from literature (Table 2). Hence, the lipidnormalized concentrations have added uncertainty, particularly for Pisidium which has a very low lipid content. This does not matter for model comparison purposes as the lipid content assumed for normalization was used as model input and hence errors in lipid-content will cancel out in model-measurement comparisons. The benthic samples may also have contained traces of sediment particles, as they were not depurated after sampling. This means that measured concentrations of (i) D4 in chironomids and D5 in Pisidium could have been diluted by presence of sediment particles ( conc $_{\text {benthos }}>$ conc $_{\text {sed }}\left(\mathrm{ng} \mathrm{g}^{-1}\right.$ ww)), while (ii) D5, D6 in chironomids and D4, D6 in Pisidium could have been contaminated by presence of sediment particles $\left(\right.$ conc $_{\text {benthos }} \leq$ conc $_{\text {sed }}\left(\mathrm{ng} \mathrm{g}^{-1}\right.$ ww $\left.)\right) .{ }^{20}$ Hence, cVMS concentrations in benthos should be considered approximate and are only used for model-measurement comparisons.

All cVMS concentrations in whole-body homogenates of sticklebacks were above LOQ (SI Table S3), with concentrations of $12.6 \pm 9,131 \pm 105$, and $6.3 \pm 3.6 \mathrm{ng} \mathrm{g}^{-1}$ ww for D4, D5, and D6, respectively $(309 \pm 226,3203 \pm 2584$, and $155 \pm 89 \mathrm{ng} \mathrm{g}^{-1}$ lipid weight $\left.(\mathrm{lw})\right)(n=5)$ (Table 2). In muscle of char and trout, D4, D5, and D6 were above LOQ in 37\%, $97 \%$, and $14 \%$ of the samples, respectively (SI Table S3). D4 and D6 were below LOQ in trout, whereas D5 ranged between $3.9-22.0 \mathrm{ng} \mathrm{g}^{-1} \mathrm{ww}\left(383-2434 \mathrm{ng} \mathrm{g}^{-1} \mathrm{lw}\right)(n=13)$. In char, D4, D5, and D6 ranged between < LOQ - 19, 7.1-124, and < LOQ - $6.1 \mathrm{ng} \mathrm{g}^{-1} \mathrm{ww}(<\mathrm{LOQ}-1295,757-8264$, and $<$ LOQ $\left.-809 \mathrm{ng} \mathrm{g}^{-1} \mathrm{lw}\right)(n=11)$, respectively (Table 2$)$. The D5 concentrations were significantly higher in char muscle (average $\left.3774 \pm 2806 \mathrm{ng} \mathrm{g}^{-1} \mathrm{lw}\right)$ ) than in trout muscle (average $855 \pm$ $\left.560 \mathrm{ng} \mathrm{g}^{-1} \mathrm{lw}\right)(p$-value $=0.001)$. Lipid-normalized D5 concentrations were also significantly higher in liver than in muscle for both trout (ratio liver/muscle $1.7 \pm 0.7, p$-value $=$ 0.01 ) and char (ratio liver/muscle $1.8 \pm 0.6, p$-value $=0.04$ ) using a paired two-tailed $t$ test with a $95 \%$ confidence level (SI 1.4).

Comparison of cVMS concentrations in fish from different aquatic systems is complicated by different hydrodynamics, exposure scenarios, and species sampled. cVMS have not been previously measured in sticklebacks, but the measured concentrations reported here are within the range of concentrations reported for other low trophic-level fish species from Lake Mjøsa and Lake Erie, although large variations have been observed (SI Table S8). ${ }^{11,13,14,45}$ cVMS concentrations in Storvannet char were higher than in char sampled from nonimpacted lakes in Nordic countries ${ }^{13,46,47}$ and from the wastewater-impacted Lake Vättern in Sweden. ${ }^{46}$ Our values were also higher than in bentho-pelagic Perch from wastewaterimpacted Swedish lakes ( $\left.\mathrm{ng}^{-1} \mathrm{ww}\right){ }^{48}$ but similar to concentrations in benthic flounder from the Humber Estuary ${ }^{43}$ and the Oslofjord ${ }^{44}$ (SI Table S8). The brown trout in Storvannet had lower D5 concentrations than brown trout in the wastewater-impacted lakes of Mjøsa and Randsfjorden, but higher concentrations than in the nonimpacted lake Femunden (SI Table S8). ${ }^{13,14,45}$ 

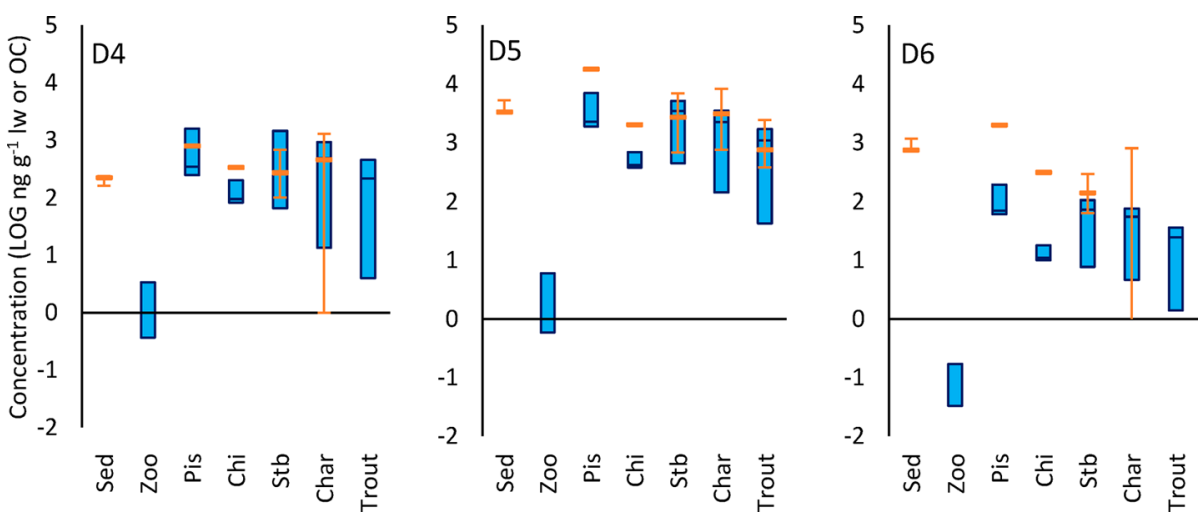

Figure 2. Median predicted concentrations (the middle bar in the blue boxes) of D4, D5, and D6, with lower and upper limits showing the predicted annual minimum and maximum concentrations, respectively. Orange lines with error bars illustrate minimum, median, and maximum of measured concentrations. Error bars are extended to the $x$-axis where there were concentrations < LOQ (D4 and D6 in char). For D6 in char, only the range (n.d., $\max$ ) in measured concentrations is included and not the median as $>50 \%$ of concentrations were below LOQ. Measured results are not included when all results were $<$ LOQ (D4 and D6 in trout). Sed $=$ Sediment, Zoo $=$ zooplankton, Pis $=$ Pisidium sp., Chi $=$ chironomids, Stb $=$ sticklebacks.

The average $\delta^{15} \mathrm{~N}$ values were significantly lower $(p=3.0 \times$ $\left.10^{-5}\right)$ in char $(10.4 \pm 1.0)$ than in trout $(12.4 \pm 0.9)$ using a two-tailed $t$ test with a $95 \%$ confidence level (Table 2). The higher trophic level of trout is caused by greater piscivory. The lower cVMS concentrations in trout compared to char can at least partially be explained by its lower dietary fraction of benthos, but also suggests some trophic dilution. There was a significant negative correlation between D5 concentrations in char muscle $\left(R^{2}=0.33, p<0.05\right)$ and $\delta^{15} \mathrm{~N}$. Ratios of average lipid-normalized D5 concentrations in fish muscle to the average OC-normalized D5 concentrations in sediments (biotasediment accumulation factor $(\mathrm{BSAF}))^{49}$ were $1.0 \pm 0.7$ (range $0.2-2.2$ ) and $0.2 \pm 0.1$ (range $0.1-0.6$ ) for char and trout, respectively. This is in agreement with previous studies of bentho-pelagic perch in Swedish lakes ${ }^{48}$ and various fish species in Lake Pepin ${ }^{10}$ where BSAFs were below or equal to 1 . In Storvannet char, BSAFs were less than or equal to 6.2 for D4 and less than or equal to 1.0 for D6. The BSAFs for D4, D5, and D6 in sticklebacks were $1.5 \pm 1.1$ (range 0.5-3.3), $0.8 \pm$ 0.7 (range 0.2-1.8), and $0.2 \pm 0.1$ (range 0.1-0.3), respectively. This indicates a higher bioaccumulation potential for D4 than for D5 which, in turn, was higher than for D6, possibly explained by reduced gut-uptake efficiency at higher $K_{\mathrm{OW}} \cdot{ }^{50}$ These observations are in agreement with previous observations for ragworm and flounder in the Humber Estuary ${ }^{43}$ and chironomid larvae and various fish species in Lake Pepin, ${ }^{10}$ and may explain why higher concentrations of D4 compared to D6 were observed in Storvannet biota, when the sediments had higher concentrations of D6 than D4. ${ }^{20}$

3.2. Model Evaluation and Application. Model predictions for PCBs in top predator fish improved when incorporating the benthic link, suggesting that this is a better representation of the Storvannet ecosystem than the pelagiconly model (SI 2.3). This agrees with knowledge of the system, where benthos is a key part of the food web, and supports application of the new bentho-pelagic model version for cVMS in this lake.

Predictions from the bentho-pelagic model are compared to measured concentrations of cVMS in Figure 2 and SI S11. In the model simulations, $f_{\text {sediment }} / f_{\text {water }}$ ratios of $10^{3}, 10^{4}$, and $10^{5}$ were assumed for D4, D5, and D6, respectively, as this scenario was judged to be in fair agreement with both (i) LOQs for water and (ii) a comparison between model predictions and measurements for fish (SI 2.4). The assumed $f_{\text {sediment }} / f_{\text {water }}$ ratios may be unrealistically high, but are consistent with our understanding that cVMS are only intermittently emitted to the lake, and rapidly removed from the water column via advection (low hydraulic retention time). ${ }^{20}$ Dynamic model simulations assuming intermittent release could explain high measured cVMS concentrations in sediment and a low water column concentration, resulting in a disequilibrium between sediment and water for most of the year. ${ }^{20}$ However, similar results could be obtained with other $f_{\text {sediment }} / f_{\text {water }}$ ratios (e.g., 100 times lower for all cVMS) (SI Figure S9), reflecting low sensitivity toward this parameter once it exceeds a certain level.

Based on these assumptions for water, median modeled concentrations in benthos and fish were all within a factor of 4 of median measured concentrations, except for predicted concentrations of D6 in benthos which were a factor of 28 lower than measurements. While all concentrations in benthos were under-predicted compared to measurements (ratios of predictions to measurements of 0.04-0.4), predicted concentrations in fish were in good agreement with measurements (ratios of predictions to measurements of $0.5-2.5$ ). The good agreement for fish is partly a result of assumed fugacities in water based on a comparison of predicted and measured concentrations in fish (and our overall understanding of the system) (SI 2.4). cVMS are not predicted to undergo trophic magnification in Storvannet. This agrees with measurements in Storvannet and elsewhere. ${ }^{9-12}$ This also agrees with predicted trophic dilution for the Oslofjord, which was explained by biotransformation and reduced gut-uptake efficiency in fish due to high $K_{\mathrm{Ow}}{ }^{24}$ However, trophic magnification for cVMS has been reported in south-Norwegian lakes. ${ }^{13,14}$

It should be stressed that there is considerable uncertainty in the overall partitioning behavior of cVMS between the three media of OC, water, and lipids at low temperatures (as is the case in Storvannet), and several combinations of $K_{\mathrm{OC}}, K_{\mathrm{OW}}$, $\Delta U_{\mathrm{OW}}$, and $\Delta U_{\mathrm{OC}}$ could lead to the same results (equifinality). ${ }^{51}$ With the measured properties used here, $K_{\mathrm{OW}}$ and $K_{\mathrm{OC}}$ are predicted to change in opposite directions with decreasing temperature, and at $0{ }^{\circ} \mathrm{C}$ they approach each other and have similar values (SI Figure S8). This is very different from their measured behavior at $25{ }^{\circ} \mathrm{C}$ where cVMS are assumed to 

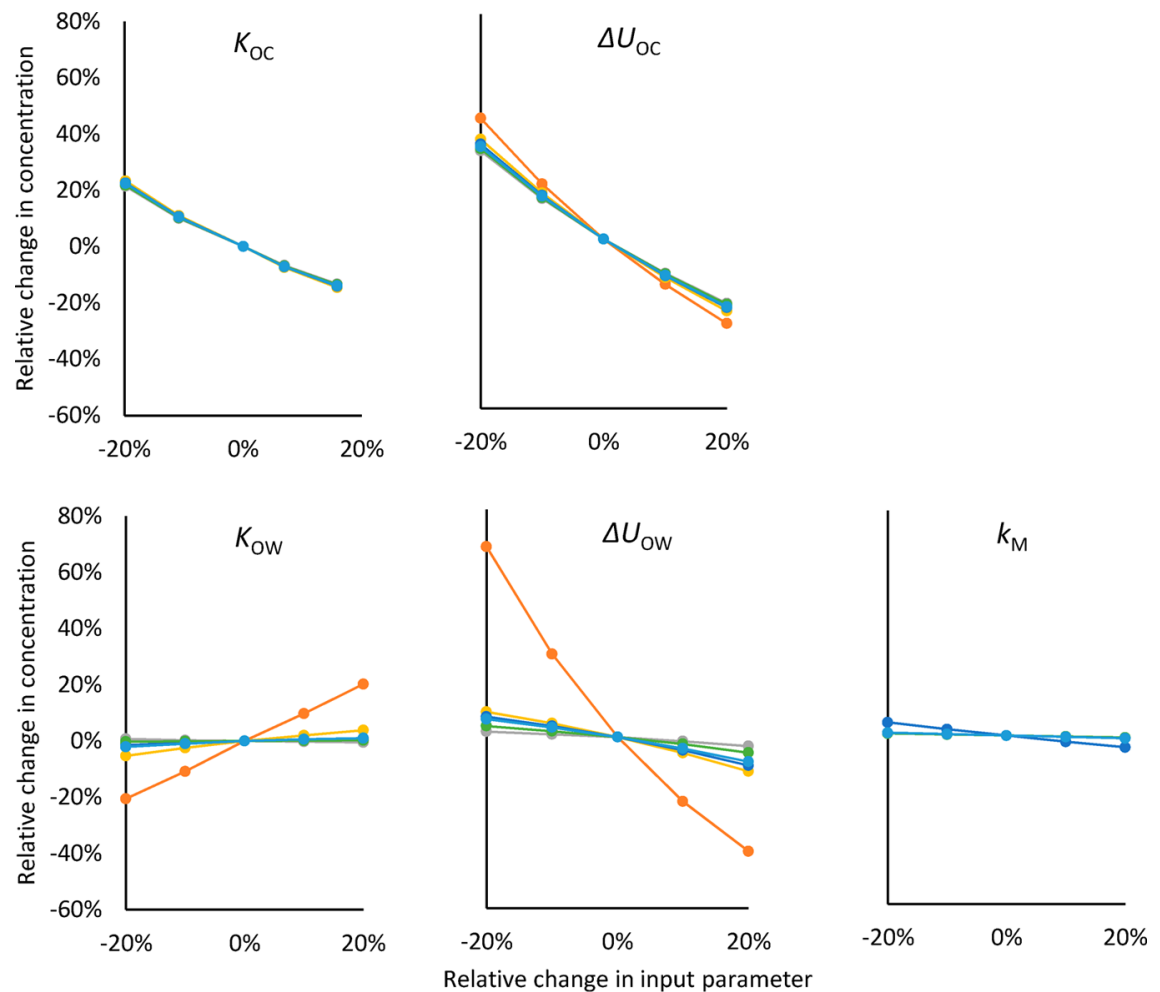

$\multimap$ Zooplankton $\multimap$ Chironomidae $\multimap$ Pisidium sp. $\multimap$ Stickleback $\multimap$ Char $\multimap$ Trout

Figure 3. Sensitivities of model predictions to changes in input parameters for D5. For $k_{\mathrm{M}}$, the rate constants have been varied individually for each species. See SI Figures S14, S15, and S17 for results for all three cVMS compounds.

partition much stronger to lipids than to OC. ${ }^{19,52}$ Here, ventilation is predicted to dominate over ingestion as the dominant source of cVMS for benthos (SI Figure S12; results only shown for D5). However, any errors in the assumed partitioning behavior between OC, water, and lipids at low temperatures, would potentially lead to errors in the predicted transfer of cVMS from sediment to benthos due to errors in predicted solvent switching. ${ }^{53}$

It is insightful to evaluate predicted fluxes (represented by model $\mathrm{N}$-values; mol $\left.\mathrm{h}^{-1}\right)^{54,55}$ for uptake and elimination of cVMS in biota. Ingestion is the dominant uptake mechanism for D5 in the three fish species in periods when the fish feed (SI Figure S12; results only shown for D5). Sticklebacks are predicted to ingest cVMS through Pisidium and chironomids, with about 50\% coming from each species (results not shown). For char and trout, the main dietary source of cVMS varies with age; benthos dominates for the young fish while the importance of fish as a source of cVMS increases with age (Figure S13; results only shown for D5). There may be individual variation between fish which is not reflected in this average scenario, particularly for char which tend to specialize on certain dietary items. Ingestion of cVMS through zooplankton is negligible for all fish species in the model (in part, reflecting the assumed fugacity ratio between sediment and water). Assumption of 100 times lower $f_{\text {sediment }} / f_{\text {water }}$ ratios, which would not significantly change predictions for fish, would predict cVMS concentrations in zooplankton to be in better agreement with measurements in other lakes. ${ }^{11,13,14,45}$ Zooplankton may be a significant source of cVMS for fish, particularly during periods when sewage overflows occur at the same time as the short plankton bloom in Storvannet.
For all three fish species, the dominant elimination mechanisms for cVMS are predicted to be fecal egestion, biotransformation and ventilation (in decreasing order of importance) (SI Figure S12; results only shown for D5). Mackay et al. ${ }^{15}$ have shown that when there is a high fugacity ratio between sediment and water (as is the case in Storvannet), elimination through ventilation may be an important loss mechanism for organic contaminants because of higher fugacity in the fish than in the water. If $K_{\mathrm{OW}}$ decreases at low temperatures, ${ }^{21}$ loss of cVMS through ventilation may be higher in lakes like Storvannet than elsewhere.

3.3. Factors Influencing Predicted Bioaccumulation Behavior of cVMS. The sensitivity analysis suggested that predicted concentrations in biota were most sensitive to changes in $K_{\mathrm{OC}}$ and $\Delta U_{\mathrm{OC}}$ (Figure 3). This is explained by (i) $K_{\mathrm{OC}}$ and $\Delta U_{\mathrm{OC}}$ controlling predicted concentrations in sediment pore water, (ii) ventilation of sediment pore water being the most important uptake mechanism for cVMS in benthos in the model, and (iii) benthos being the most important source of cVMS for fish. Predicted concentrations in biota were less sensitive toward changes in $K_{\mathrm{OW}}$ and $\Delta U_{\mathrm{OW}}$, except for predicted concentrations in zooplankton which are directly calculated from temperature-corrected $K_{\mathrm{OW}}$ and fugacity in lake water (Figure 3 ).

$K_{\mathrm{OC}}$ and $\Delta U_{\mathrm{OC}}$ were also important for model predictions of environmental fate of cVMS in the physical environment in Storvannet. ${ }^{20}$ In the simulations for the physical environment, $\Delta U_{\mathrm{OC}}$ was assumed equal to $\Delta U_{\mathrm{OW}}$ in the absence of available measurements of $\Delta U_{\mathrm{OC}}$. If the new measured $\Delta U_{\mathrm{OC}}$ had been used instead, ${ }^{23}$ cVMS would have been predicted to partition more to sediment solids with lower predicted concentrations in water and pore water and higher predicted overall persistence. 
Inverse-modeled cVMS emissions to the lake would also be lower and in better agreement with measured concentrations in sewage and our (limited) understanding of emission patterns. ${ }^{20}$ For the Storvannet food web, incorporation of the new $\Delta U_{\mathrm{OC}}$ also resulted in improved predictions of concentrations in biota compared to measurements, as an assumption of $\Delta U_{\mathrm{OC}}=$ $\Delta U_{\text {OW }}$ would have led to a considerable overprediction of cVMS concentrations in fish (SI Figure S16). However, predicted concentrations of D6 in benthos would have been in better agreement with measurements (SI Figure S16), indicating that $\Delta U_{\mathrm{OC}}$ for D6 could be lower than assumed here. $^{23}$

Given the considerable difference between $K_{\mathrm{OC}}$ and $K_{\mathrm{OW}}{ }^{18}$ and between $\Delta U_{\mathrm{OC}}$ and $\Delta U_{\mathrm{OW}}{ }^{23}$ for cVMS, the assumption that storage lipid can be represented by octanol is also uncertain. $K_{\mathrm{OW}}$ is believed to represent partitioning of cVMS to storage lipids at room temperature, but there is still little experimental evidence documenting that this is the case. ${ }^{40,41}$ This assumption is even less robust for membrane lipids. ${ }^{40}$ The temperature dependence of cVMS partitioning between water and storage lipids has been argued to be similar to $\Delta U_{\mathrm{OW}}$ when derived from measured $\Delta U_{\text {air-storage lipid }}$ and $\Delta U_{\text {air-water }}{ }^{56}$ However, $\Delta U_{\text {lipid-water }}$ for cVMS has never been experimentally measured. This adds uncertainty to the predicted cVMS concentrations in biota.

Predicted concentrations of D4 and D5 in char and trout were not very sensitive to changes in the biotransformation rate constant $\left(k_{\mathrm{M}}\right)$ (Figure 3), because of efficient removal through ventilation (Section 3.2). Sensitivities to $k_{\mathrm{M}}$ were higher for all cVMS in stickleback, and for D6 in all fish species (Figure 3). The reason for higher sensitivity to changes in $k_{\mathrm{M}}$ for D6 is because it is not as efficiently removed through ventilation $(\mathrm{N}$ value $10^{-16}-10^{-17} \mathrm{~mol} \mathrm{~h}^{-1}$ ) compared to D5 and D4 ( $N$-value $\left.10^{-13}-10^{-14} \mathrm{~mol} \mathrm{~h}^{-1}\right)$. Best predictions of $\mathrm{cVMS}$ concentrations in benthic animals were achieved assuming no biotransformation. Assuming the same $k_{\mathrm{M}}$ in benthos as in fish predicted $70-80 \%$ lower concentrations in benthos compared to when assuming no biotransformation.

The good agreement between predictions and measurements for PCBs in Storvannet, suggests that inconsistencies for cVMS more likely result from the properties of cVMS than from the description of the food web in the model. However, there could also be errors in model assumptions, exemplified by a measured dietary chemical absorption of PCB 153 in the crustacean Diporeia twice as high than calculated by the equation in our model (SI 2.1.4.2), ${ }^{3,57}$ and the fact that the equation used for diet uptake rate for benthos is based on data for trout. ${ }^{37}$ Moreover, the parametrization for the species in Storvannet also involve assumptions and uncertainties. For example, replacing $10 \%$ of the diet of the predator/deposit feeder with lipids instead of organic carbon, would increase its predicted concentrations of D4, D5, and D6 with $14 \%, 8 \%$, and $22 \%$, respectively. Likewise, the predicted concentrations in fish are sensitive to their assumed dietary compositions, and inclusion of less (or more) benthos and fish in their diet compared to zooplankton would decrease (or increase) predicted concentrations in fish. Moreover, seasonality (in, e.g., lipid dynamics, growth, and spawning) is not adequately represented in the model, which could influence predicted concentrations in biota. This should be looked into in future studies.

Possible explanations for the fact that concentrations of cVMS in benthic animals were underestimated by the model while concentrations in fish were in agreement with measure- ments include (i) poor representation of solvent switching between sediment and benthos (possibly resulting from poorly constrained partition coefficients between water, OC, and lipids at low temperatures); (ii) errors in the description of the food web for fish (a lower dietary fraction of benthos with higher cVMS concentrations may have provided better agreement with measured data); (iv) underestimation of elimination rates in fish; and/or ( $v$ ) overestimation of ingestion rates for fish compared to their actual food consumption in Storvannet. One of the key uncertainties is the lipid-water-OC partitioning for cVMS at low temperatures. Using the $K_{\mathrm{OC}}$ by Kozerski et al. ${ }^{58}$ and the same temperature dependency for $K_{\mathrm{OC}}$ as for $K_{\mathrm{OW}}$ would give predicted concentrations 140-440 times higher than what we predicted (depending on cVMS compound and species). A better knowledge of both the partitioning properties and biotransformation of cVMS at low temperatures is urgently needed to better constrain model predictions of trophic transfer and improve our understanding of cVMS behavior in high latitude systems. Also, sensitive methods for measuring cVMS at low concentrations in receiving waters is needed. A good understanding of cVMS behavior in aquatic systems is particularly important in light of the European restriction on D4 and D5 in wash-off products which is underway, ${ }^{5}$ for which protection of biota living in aquatic systems receiving local emissions of cVMS is a key objective.

\section{ASSOCIATED CONTENT}

S Supporting Information

The Supporting Information is available free of charge on the ACS Publications website at DOI: 10.1021/acs.est.7b03083.

Detailed descriptions of laboratory procedures, measurement results including sample characteristics, fish liver tissues, and comparison to literature, and model equations, parametrization, and results (PDF)

\section{AUTHOR INFORMATION}

\section{Corresponding Author}

*Phone: +47 638980 00; e-mail: isk@nilu.no. ORCID

Ingjerd S. Krogseth: 0000-0002-6063-6655

Notes

The authors declare no competing financial interest.

\section{ACKNOWLEDGMENTS}

We are grateful to the Research Council of Norway (project numbers 222259 and 244298) and the FRAM Flagship Hazardous substances-effects on ecosystems and human health for financing the study, and to Hammerfest municipality, local fishermen, and Line Christoffersen for assistance. E.U. also acknowledges funding through the Baltic Sea Adaptive Management (BEAM) project at Stockholm University.

\section{REFERENCES}

(1) Brooke, D.; Crookes, M.; Gray, D.; Robertson, S. Environmental risk assessment report: Decamethylcyclopentasiloxane; Environment Agency of England and Wales: Bristol, U.K., 2009.

(2) Brooke, D.; Crookes, M.; Gray, D.; Robertson, S. Environmental risk assessment report: Octamethylcyclotetrasiloxane; Environment Agency of England and Wales: Bristol, U.K., 2009.

(3) Brooke, D.; Crookes, M.; Gray, D.; Robertson, S. Environmental risk assessment report: Dodecamethylcyclohexasiloxane; Environment Agency of England and Wales: Bristol, U.K., 2009. 
(4) European Chemicals Agency (ECHA). Member state committe (MSC) opinion on persistency and bioaccumulation of octamethylcyclotetrasiloxane (D4) EC Number: 209-136-7 CAS Number: 556-67-2 and decamethylcyclopentasiloxane (D5) EC Number: 208-764-9 and CAS Number 541-02-6 according to a MSC mandate, adopted on 22 April 2015; European Chemicals Agency (ECHA): Helsinki, Finland, 2015.

(5) Committee for Risk Assessment (RAC), Committee for SocioEconomic Analysis (SEAC). Background Document to the Opinion on the Annex $X V$ dossier proposing restrictions on Octamethylcyclotetrasiloxane (D4) and Decamethylcyclopentasiloxane (D5). ECHA/RAC/RES-O0000001412-86-97/D, ECHA/SEAC/RES-O-0000001412-86-109/ F; European Chemicals Agency (ECHA): Finland, 2016.

(6) Gobas, F. A. P. C.; Powell, D. E.; Woodburn, K. B.; Springer, T.; Huggett, D. B. Bioaccumulation of decamethylpentacyclosiloxane (D5): A review. Environ. Toxicol. Chem. 2015, 34, 2703-2714.

(7) Kim, J.; Gobas, F. A.; Arnot, J. A.; Powell, D. E.; Seston, R. M.; Woodburn, K. B. Evaluating the roles of biotransformation, spatial concentration differences, organism home range, and field sampling design on trophic magnification factors. Sci. Total Environ. 2016, 551$552,438-51$.

(8) Mackay, D. Risk assessment and regulation of D5 in Canada: Lessons learned. Environ. Toxicol. Chem. 2015, 34, 2687-2688.

(9) Powell, D. E.; Durham, J.; Huff, D. W.; Böhmer, T.; Gerhards, R.; Koerner, M. Bioaccumulation and Trophic Transfer of Cyclic Volatile Methylsiloxane (cVMS) Materials in the Aquatic Marine Food Webs of the Inner and Outer Oslofjord, Norway; HES study no. 11060-108; Internal report conducted for Centre Européen des Silicones; Dow Corning Corporation, Auburn, MI, 2010.

(10) Powell, D. E.; Woodburn, K. B.; Drotar, K. D.; Durham, J.; Huff, D. W. Trophic Dilution of Cyclic Volatile Methylsiloxane (cVMS) Materials in a Temperate Freshwater Lake; HES study no. 10771-108; Internal report conducted for Centre Européen des Silicones; Dow Corning Corporation, Auburn, MI, 2009.

(11) McGoldrick, D. J.; Chan, C.; Drouillard, K. G.; Keir, M. J.; Clark, M. G.; Backus, S. M. Concentrations and trophic magnification of cyclic siloxanes in aquatic biota from the Western Basin of Lake Erie, Canada. Environ. Pollut. 2014, 186, 141-148.

(12) Powell, D. E.; Suganuma, N.; Kobayashi, K.; Nakamura, T.; Ninomiya, K.; Matsumura, K.; Omura, N.; Ushioka, S. Trophic dilution of cyclic volatile methylsiloxanes (cVMS) in the pelagic marine food web of Tokyo Bay, Japan. Sci. Total Environ. 2017, 578, 366-382.

(13) Borgå, K.; Fjeld, E.; Kierkegaard, A.; McLachlan, M. S. Consistency in trophic magnification factors of cyclic methyl siloxanes in pelagic freshwater food webs leading to brown trout. Environ. Sci. Technol. 2013, 47, 14394-14402.

(14) Borgå, K.; Fjeld, E.; Kierkegaard, A.; McLachlan, M. S. Food web accumulation of cyclic siloxanes in Lake Mjøsa, Norway. Environ. Sci. Technol. 2012, 46, 6347-6354.

(15) Mackay, D.; Celsie, A. K. D.; Arnot, J. A.; Powell, D. E. Processes influencing chemical biomagnification and trophic magnification factors in aquatic ecosystems: Implications for chemical hazard and risk assessment. Chemosphere 2016, 154, 99-108.

(16) Whelan, M. J.; Sanders, D.; van Egmond, R. Effect of Aldrich humic acid on water-atmosphere transfer of decamethylcyclopentasiloxane. Chemosphere 2009, 74, 1111-1116.

(17) Whelan, M. J.; van Egmond, R.; Gore, D.; Sanders, D. Dynamic multi-phase partitioning of decamethylcyclopentasiloxane (D5) in river water. Water Res. 2010, 44, 3679-3686.

(18) Panagopoulos, D.; Jahnke, A.; Kierkegaard, A.; MacLeod, M. Organic carbon/water and dissolved organic carbon/water partitioning of cyclic volatile methylsiloxanes: Measurements and polyparameter linear free energy relationships. Environ. Sci. Technol. 2015, 49, 1216112168.

(19) Xu, S.; Kozerski, G.; Mackay, D. Critical review and interpretation of environmental data for volatile methylsiloxanes: partition properties. Environ. Sci. Technol. 2014, 48, 11748-11759.
(20) Krogseth, I. S.; Whelan, M. J.; Christensen, G. N.; Breivik, K.; Evenset, A.; Warner, N. A. Understanding of cyclic volatile methyl siloxane fate in a high latitude lake is constrained by uncertainty in organic carbon-water partitioning. Environ. Sci. Technol. 2017, 51, 401-409.

(21) Xu, S.; Kropscott, B. Evaluation of the three-phase equilibrium method for measuring temperature dependence of internally consistent partition coefficients (KOW, KOA, and KAW) for volatile methylsiloxanes and trimethylsilanol. Environ. Toxicol. Chem. 2014, 33, $2702-2710$

(22) Xu, S. H.; Kozerski, G. E. Assessment of the Fundamental Partitioning Properties of Permethylated cyclosiloxanes; SETAC Europe, Porto, Portugal, 2007.

(23) Panagopoulos, D.; Jahnke, A.; Kierkegaard, A.; MacLeod, M. Temperature dependence of the organic carbon/water partition ratios (KOC) of volatile methylsiloxanes. Environ. Sci. Technol. Lett. 2017, 4, 240-245.

(24) Whelan, M. J.; Breivik, K. Dynamic modelling of aquatic exposure and pelagic food chain transfer of cyclic volatile methyl siloxanes in the Inner Oslofjord. Chemosphere 2013, 93, 794-804.

(25) McLachlan, M. S.; Kierkegaard, A.; Hansen, K. M.; van Egmond, R; Christensen, J. H.; Skjøth, C. A. Concentrations and fate of decamethylcyclopentasiloxane $(\mathrm{D}(5))$ in the atmosphere. Environ. Sci. Technol. 2010, 44, 5365-5370.

(26) Krogseth, I. S.; Kierkegaard, A.; McLachlan, M. S.; Breivik, K.; Hansen, K. M.; Schlabach, M. Occurrence and seasonality of cyclic volatile methyl siloxanes in Arctic air. Environ. Sci. Technol. 2013, 47, 502-509.

(27) Kim, J.; Mackay, D.; Powell, D. E. Roles of steady-state and dynamic models for regulation of hydrophobic chemicals in aquatic systems: A case study of decamethylcyclopentasiloxane (D5) and PCB-180 in three diverse ecosystems. Chemosphere 2017, 175, 253268.

(28) Czub, G.; McLachlan, M. S. A food chain model to predict the levels of lipophilic organic contaminants in humans. Environ. Toxicol. Chem. 2004, 23, 2356-2366.

(29) Rikardsen, A. H.; Amundsen, P. A.; Bjørn, P. A.; Johansen, M. Comparison of growth, diet and food consumption of sea-run and lake-dwelling Arctic charr. J. Fish Biol. 2000, 57, 1172-1188.

(30) Rikardsen, A. H.; Svenning, M. A.; Klemetsen, A. The relationships between anadromy, sex ratio and parr growth of Arctic charr in a lake in North Norway. J. Fish Biol. 1997, 51, 447-461.

(31) Christensen, G. N.; Evenset, A.; Dahl-Hansen, G.; Götsch, A. Storvatn i Hammerfest kommune. Undersøkelse av miljøgifter $i$ vann, sediment og fisk, 2008; Akvaplan-niva AS: Tromsø, Norway, 2009.

(32) Mousavi, S. K.; Amundsen, P.-A. Seasonal variations in the profundal Chironomidae (Diptera) assemblage of a subarctic lake. Boreal Environ. Res. 2012, 17, 102-112.

(33) Rikardsen, A. H.; Amundsen, P. A.; Bodin, P. J. Foraging behaviour changes of Arctic charr during smolt migration in northern Norway. J. Fish Biol. 2002, 60, 489-491.

(34) Sánchez-Hernández, J.; Amundsen, P.-A. Trophic ecology of brown trout (Salmo trutta L.) in subarctic lakes. Ecol. Freshw. Fish 2015, 24, 148-161.

(35) Amundsen, P.-A.; Knudsen, R. Winter ecology of Arctic charr (Salvelinus alpinus) and brown trout (Salmo trutta) in a subarctic lake, Norway. Aquat. Ecol. 2009, 43, 765-775.

(36) Folch, J.; Lees, M.; Sloane Stanley, G. H. A simple method for the isolation and purification of total lipides from animal tissues. J. Biol. Chem. 1957, 226, 497-509.

(37) Arnot, J. A.; Gobas, F. A food web bioaccumulation model for organic chemicals in aquatic ecosystems. Environ. Toxicol. Chem. 2004, 23, 2343-2355

(38) Rikardsen, A. H.; Amundsen, P. A.; Bodin, P. J. Growth and diet of anadromous Arctic charr after their return to freshwater. Ecol. Freshw. Fish 2003, 12, 74-80.

(39) Seth, R.; Mackay, D.; Muncke, J. Estimating the organic carbon partition coefficient and its variability for hydrophobic chemicals. Environ. Sci. Technol. 1999, 33, 2390-2394. 
(40) Seston, R. M.; Powell, D. E.; Woodburn, K. B.; Kozerski, G. E.; Bradley, P. W.; Zwiernik, M. J. Importance of lipid analysis and implications for bioaccumulation metrics. Integr. Environ. Assess. Manage. 2014, 10, 142-144.

(41) Jahnke, A.; Holmbäck, J.; Andersson, R. A.; Kierkegaard, A.; Mayer, P.; MacLeod, M. Differences between lipids extracted from five species are not sufficient to explain biomagnification of nonpolar organic chemicals. Environ. Sci. Technol. Lett. 2015, 2, 193-197.

(42) Woodburn, K.; Drottar, K.; Domoradzki, J.; Durham, J.; McNett, D.; Jezowski, R. Determination of the dietary biomagnification of octamethylcyclotetrasiloxane and decamethylcyclopentasiloxane with the rainbow trout (Oncorhynchus mykiss). Chemosphere 2013, 93, 779-788.

(43) Kierkegaard, A.; van Egmond, R.; McLachlan, M. S. Cyclic volatile methylsiloxane bioaccumulation in flounder and ragworm in the Humber Estuary. Environ. Sci. Technol. 2011, 45, 5936-5942.

(44) Ruus, A.; Allan, I.; Beylich, B.; Bæk, K.; Schlabach, M.; Helberg, M. Environmental Contaminants in an Urban Fjord; The Norwegian Environment Agency: Oslo, Norway, 2014.

(45) Fjeld, E.; Bæk, K.; Rognerud, S.; Rundberget, J. T.; Schlabach, M.; Warner, N. A. Environmental pollutants in large Norwegian lakes, 2013; The Norwegian Environment Agency: Oslo, Norway, 2014.

(46) Kierkegaard, A.; Adolfsson-Erici, M.; McLachlan, M. S. Determination of cyclic volatile methylsiloxanes in biota with a purge and trap method. Anal. Chem. 2010, 82, 9573-9578.

(47) Kaj, L.; Schlabach, M.; Andersson, J.; Cousins, A. P.; Schmidbauer, N.; Brorström-Lundén, E. Siloxanes in the Nordic Environment; Nordic Council of Ministers: Copenhagen, Denmark, 2005.

(48) Kierkegaard, A.; Bignert, A.; McLachlan, M. S. Bioaccumulation of decamethylcyclopentasiloxane in perch in Swedish lakes. Chemosphere 2013, 93, 789-793.

(49) Burkhard, L. Estimation of Biota Sediment Accumulation factor (BSAF) from Paired Observations of Chemical Concentrations in Biota and Sediment; U.S. Environmental Protection Agency, Ecological Risk Assessment Support Center: Cincinnati, OH, 2009.

(50) Kelly, B. C.; Gobas, F. A. P. C.; McLachlan, M. S. Intestinal absorption and biomagnification of organic contaminants in fish, wildlife, and humans. Environ. Toxicol. Chem. 2004, 23, 2324-2336.

(51) Beven, K.; Freer, J. Equifinality, data assimilation, and uncertainty estimation in mechanistic modelling of complex environmental systems using the GLUE methodology. J. Hydrol. 2001, 249, $11-29$.

(52) Gobas, F. A. P. C.; Xu, S.; Kozerski, G.; Powell, D. E.; Woodburn, K. B.; Mackay, D.; Fairbrother, A. Fugacity and activity analysis of the bioaccumulation and environmental risks of decamethylcyclopentasiloxane (D5). Environ. Toxicol. Chem. 2015, 34, 2723-2731.

(53) Macdonald, R.; Mackay, D.; Hickie, B. Contaminant amplification in the environment. Environ. Sci. Technol. 2002, 36, $456 \mathrm{~A}-462 \mathrm{~A}$

(54) Mackay, D. Finding fugacity feasible. Environ. Sci. Technol. 1979, 13, 1218-1223.

(55) Mackay, D. Multimedia Environmental Models. The Fugacity Approach, 2nd ed.; Lewis Publishers: Boca Raton, FL, 2001.

(56) Kozerski, G. E.; McNett, D. Determination of storage lipid-to-air partition coefficients and their temperature dependence for Octamethylcyclotetrasiloxane (D4; CAS 556-67-2), Decamethylcyclopentasiloxane (D5; CAS 541-02-6) and Dodecamethylcyclohexasiloxane (D6; CAS 540-97-6); HES study no. 17240-108; Internal report conducted for Centre Européen des Silicones; Dow Corning Corporation: Auburn, MI, 2015.

(57) Kukkonen, J.; Landrum, P. F. Measuring assimilation efficiencies for sediment-bound $\mathrm{PAH}$ and $\mathrm{PCB}$ congeners by benthic organisms. Aquat. Toxicol. 1995, 32, 75-92.

(58) Kozerski, G. E.; Xu, S.; Miller, J.; Durham, J. Determination of soil-water sorption coefficients of volatile methylsiloxanes. Environ. Toxicol. Chem. 2014, 33, 1937-1945. 